\title{
Undertaking historic building surveys - An effective approach
}

Received (in revised form): 31st August, 2005

\begin{abstract}
Bob Hill MRICS, MIFA
is a chartered building surveyor who is also an archaeologist with over 35 years' experience in both the commercial property industry and heritage conservation. From an early beginning (aged seven) he was actively involved with field archaeology before becoming more thoroughly involved with the construction and property professions. In succeeding years he has always worked within historic sites and properties, developing this as a specialisation about which he has subsequently written and lectured. He has worked mostly in private practice, but also for government development agencies where he helped to promote the principle of historic building re-use. Bob currently works with Conservation Management, a specialist division of Wessex Archaeology, one of Europe's largest independent, multi-discipline, commercial archaeological contracting and consultancy organisations. This section handles all matters concerning the conservation and management of any form of man-made structure, building or landscape, extending from prehistoric earthworks, Roman field systems, through medieval battlefields and 17th-century parkland to Cold War tank garages. The team provides a wide range of assistance from practical hands-on maintenance repair advice and specification, through conservation plan development, building and landscape surveying and recording, to commercial regeneration and development planning.
\end{abstract}

\begin{abstract}
There is a growing difference of opinion as to what an historic building survey should comprise. This disagreement exists largely between those surveyors who have traditionally measured and drawn buildings and sites as just a surveying job and those who have an understanding of heritage structures and sites. It is a gap that is widening because of the increasing level of information that is being requested by local authority planning conservation staff and archaeologists. Similarly, more information is being requested as part of the planning process, either to record buildings that are about to be altered or as part of the pre-planning negotiation discussions; this generally requires a higher level of analysed and integrated information to be provided than has been asked for in the past. Meeting these new demands requires additional skills and abilities from the person carrying out the survey. It is not just collecting site information but collating historical background information as well. While this additional work may necessitate increased fees, if carried out at the appropriate time, interpreted and used correctly, it can produce cost savings across the construction project.
\end{abstract}

\section{Keywords:}

historic building survey, measured survey, desk-based assessment (DBA), building analysis

\section{INTRODUCTION - WHAT IS AN HISTORIC BUILDING?}

'A building is a building, so it is the same practice and procedure to carry out a measured survey on one that is four years old as it is on one that is 


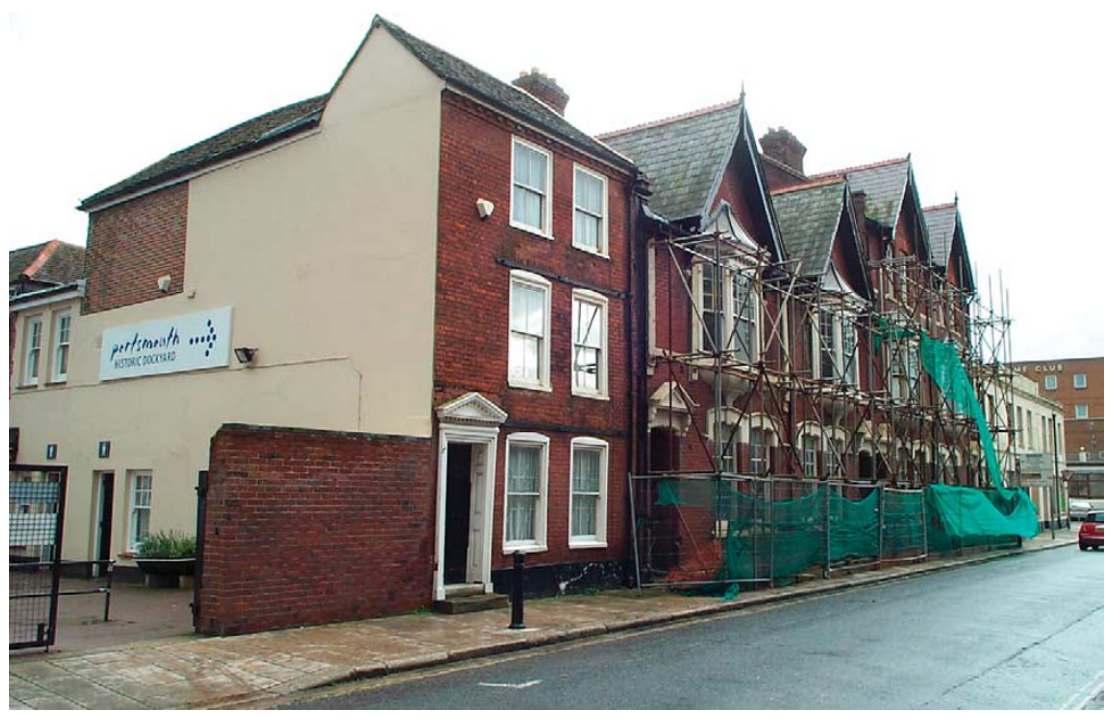

Figure 1: A typical group of listed (grade II) and unlisted buildings within a conservation area subject to a full historic building survey as part of a redevelopment scheme

four hundred years old.' In the minds of many 'surveyors', this is an unchallenged mantra. The thought process goes on from there to accept that there is no need for a good surveyor even to bother themselves with what they are dealing with and what the information is that they need to capture.

Before considering what there is about an old property that marks it out from a new one, it may be appropriate to address what is meant by 'old' in building terms. Generally, the term covers buildings that are not built with contemporary techniques and materials by 'traditional' or even vernacular methods. For the purpose of this paper it is taken generally as anything that is pre-1840, the period accepted as being the baseline age for a property to be worthy of listing as a building of architectural and/or historic interest (see Figure 1), although there are more modern structures that are listed. Since that period there has been a steady and insidious control of building forms and methods by regulations (everything from building control to public health legislation) coupled with the increasing use of machine-made materials.

In the 160 years or so that have followed, there appears to have been less general change and adaptation of buildings although it is difficult to determine why. It may be because of constraints imposed by legislation or due to the lack of what is almost spontaneity in the way property is considered: as a flexible object that can be altered and adapted at will to suit the needs of its occupants. It may be that the changes brought about by the massive amount of building that has occurred since the $1840 \mathrm{~s}$ have made it easier and cheaper to move (or at least until very recent times) than to re-shape a building. As a result, there is not the level of inconsistency or idiosyncrasy seen in buildings of preceding times, a variance that means such buildings need to be considered on an individual basis. 


\section{WHAT MAKES AN HISTORIC BUILDING SURVEY DIFFERENT?}

There is generally only one reason why most commercial surveyors will need to carry out a measured survey of an old/historic building and that is because it is to be altered or adapted in some way. The drawings this survey produces will be used by the designers as a base from which to plan the works; however, many specialist historic building surveyors (sometimes and wrongly called buildings' archaeologists) also find themselves measuring buildings that are at the end of their lives and are going to be demolished. In such cases the work is to produce an obituary for that structure in the form of a record drawing. It is often only

A good survey is a tool, not a memory at that time that an historic structure is revealed, rather like a butterfly

emerging for a brief moment of glory before being swept away.

Historic building surveyors do not only get involved with those pieces of built heritage that are in the process of being lost. Frequently they deal with properties that have been surveyed and drawn already within a traditional philosophy because so much information has been missed. Mostly this form of survey is carried out as the result of a planning consent condition imposed after the designs have been completed, planning consent has been granted for the proposal and work is about to commence on site. This commonly requires a specialist historic building surveyor, who is usually a member of the Institute of Field Archaeologists (IFA), to produce a survey that contains a specified minimum level of information and interpretation which normally will be higher than that found on a standard set of measured drawings.

The result is that there is a repeat survey of the building as it is to produce an archaeological record before it is changed. This can be combined with historical research so that the property is fully analysed. Such work, to some extent, will duplicate the work already carried out by the original surveyor, at further cost to the site owner. The level and type of information that can be recovered, however, is often far greater than the original survey, tells more about the property, and would have been more useful to the designer at an early stage in the work.

But this retrospective survey procedure is in the process of changing rapidly. In England, Planning Policy Guidance (PPG) notes 15 and 16 (ODPM, current) (with similar guidance in Wales and Scotland) dealing with development concerning historic buildings and archaeological sites for several years have recommended that as much information as possible is obtained by a local planning authority (LPA) as early in the consideration process as possible. This enables decisions affecting heritage, either above or below ground, to be considered properly with all the relevant information available. While this advice has been frequently ignored by many LPAs in the past, there is now an increasing move towards these objectives with new guidance being issued by national heritage bodies.

Now the value and work of specialist historic building surveyors is becoming more recognised and appreciated, they are being brought in as integral members of the design team. Historic building surveyors bring a new range of specialist skills beyond just surveying, combining modern 


\section{A good historic building surveyor reads old property}

and traditional building knowledge and pathology, architectural history and the ability to 'read' and analyse a structure. These skills are further augmented by the ability to understand the economics of modern repair and conservation and balance them with modern commercial property demands. Most of this is also normally outside the remit of a buildings' archaeologist. In addition to these skills comes an understanding of survey techniques ranging from traditional hand measuring with tape and rod through to the use of real-time plotting with a total station, laser scanning and the use of photogrammetry.

\section{BASIC SURVEY STANDARDS}

At the start of each job it is necessary to have a full understanding of what is to happen to the site and what information is required by the design team. In addition, the background information required by the LPA's development control and conservation staff, archaeologist/heritage officer and national heritage body (English Heritage, CADW, Historic Scotland etc) needs to be understood. This whole approach moves the consideration of heritage (including standing and buried archaeology) from being something that is ignored for as long as possible to a proper position in the design/build programme. The aim is to extract as much information from a site as possible as part of a single operation, information that can be used repeatedly throughout the development process. A very high return can be achieved by this means on fees disbursed in the early stages, and these fees may even be offset by resultant savings made elsewhere.

It should be remembered that a site is more than just a building; it is the land on which it sits, the area in which it is located and the date when this all took place. To achieve a thorough understanding, all of these individual items need to be considered as part of a full survey of a site. While much of this is far removed from a traditional site survey, it is all information that needs to be considered to enable a full and proper understanding of what is being dealt with.

Two parts of a full historic survey that start almost in tandem are the desk-based assessment (DBA) and the actual measured survey of the building/site. These will be combined to enable a full historical analysis of the site to be achieved. When coupled with a thorough condition survey, a full statement of significance can be arrived at. This considers the results of the survey and sets down the significance or otherwise of the site, so it is fully understood in terms of its heritage. It is after this stage, when all the background information about the site has been collated and the statement of significance prepared that there will flow conservation policies, mitigation actions and the start of the main design process.

The majority of the historic building survey work carried out (measured survey, DBA, photographic record etc) in England for the last few years has been based on a standard specification issued by the former Royal Commission for the Historic Monuments of England (RCHME, 1996) with similar documentation for Wales and Scotland. Since the absorption of the RCHME by English Heritage there has been no other comparative document issued so this is still the standard by which practical fieldwork of this type is both ordered and monitored. The specification sets a 


\section{Historic building surveys should be to recognised standards}

minimum standard of work to be carried out over four levels of survey, dependent on the importance of the site and the corresponding level of information that is considered necessary to be extracted and collated. For the purposes of this paper, reference will be based on the RCHME (1996) specification while acknowledging the other appropriate regional guidelines.

Within the specification there are four levels of survey standard suggested corresponding to varying degrees or requirements of information recovery.

- Level I: the most basic and comprising little more than a note of the location of the site, what it is, ideally including a sketch plan and whether there are any notable aspects or features.

- Level II: a slightly more advanced recording standard requiring at least a scale or dimensioned plan of a typical floor and a minimum level of documentary research, ideally accompanied by general photographs of the site/building.

- Level III: this is a good all-round level requiring scale plans of all floors, elevations and cross sections. Joinery and other architectural details are either drawn or photographed to a good standard with the inclusion of scales within the shot. It is accompanied by a thorough DBA and photographic record of the building and its setting in general.

- Level IV: this is the highest level of building recording and even the RCHME suggests that it will be seldom used. It is necessary to record to a very fine detail to deliver both measured drawn output and highquality photographs.

For most historic building surveys that will be commercially viable, the level III standard of work should be considered as a minimum. Level I is of little commercial value being effectively a 'drive by' approach to produce a simple identification of a building and level II is a rung up from there, being a slightly amplified version. Finally, level IV is very much an all-encompassing approach, which might be appropriate for conducting a detailed survey of the staterooms of Buckingham Palace.

\section{DOCUMENTARY RESEARCH}

The commencement of the assessment of the site, and therefore any buildings, is often done by undertaking a documentary research study of the site. This again is carried out in line with the RCHME (1996) specification for the particular level that has been either specified or adopted. Most commonly, for the survey to have any effective value, it is carried out to level III. Normally this would involve a trawl of all readily accessible documentary sources relating to the building, but would not be necessarily a definitive research project. It should be sufficient to form a good understanding of the history and development of the site/building and to do this requires visits to the relevant record offices and archives as well as utilising other research sources.

An historical perspective of the building then can be delivered in report form to show as clearly as possible an account of the site from the earliest 


\section{Better information can lead to better design and conservation}

time that it is possible to determine. To be fully effective this needs to be combined with a calendar of events as well as a bibliography of the sources used. From such research it is often possible to show the various construction dates, and sometimes it is possible to suggest what building materials were used as well as their sources. This report then can be used to inform the conservation designs and give external heritage and conservation bodies the reassurance that an adequate level of research and therefore a proper understanding of the nature of the building have been achieved.

To enhance the documentary study of the building it is often possible to produce a set of phased drawings to show the development of the site graphically. This translates the findings from one's historical research work to the plans of the building as it is found standing today. To do this it is necessary to take the results of the historical analysis and attempt to relate significant comparative events within it to the development of the site/building and so determine its pattern of growth. This is where it is important to employ a thorough knowledge of the appropriate forms of building construction and development as a means of appraising the site and possibly also refining previously conceived views of its history.

The phased drawings can be incorporated within the final report along with the historic analysis so as to provide a fully annotated description of the building for general information. Again, the report will be produced in line with the general specification for written accounts, as outlined by the RCHME (1996) or equivalent other regional guidelines. When the report is combined with the previously undertaken measured survey, a full analysis of the building will have been arrived at to the required standard.

\section{PHOTOGRAPHIC RECORDING}

A full photographic survey of the site will need to be carried out. This will consist of recording by means of colour slides or digital images, as considered appropriate, together with black and white prints. This survey will include coverage of all external elevations, with all architectural details separately photographed, as well as the setting of the structure(s) within the site and its surroundings. A photographic scale should be included within the shot frame where appropriate (see Figure 2). The photographic record will be accompanied by a photographic register detailing (as a minimum) a brief description of the subject and the location and direction of each shot.

\section{MEASURED SURVEY}

A level III building record/survey requires a scaled plan of each floor, with all associated mezzanines, stairs etc, related to full elevations as well as the production of appropriate sections. This is not just a simple exercise to show the building as it is, but also how it has developed. Construction joints must be shown along with blocked and altered openings, such as doors and windows, with adequate definition to mark out the differing phases of these historical works. Similarly, the drawings need to show the full level of irregularity in an historic building whatever view plane is being considered; rooms are seldom anywhere near square, floors are 


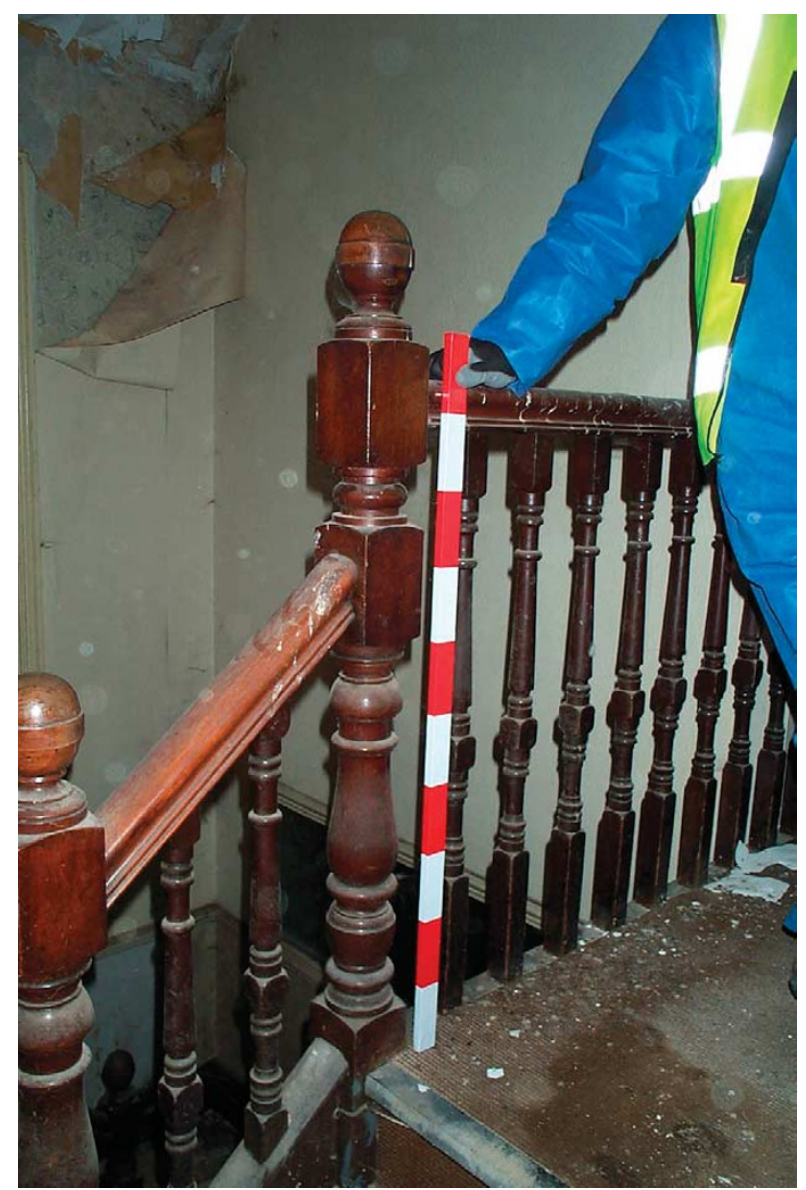

Figure 2: Typical internal detail photographed to RCHME (1996) specification level III

rarely level and walls are invariably out of plumb. The RCHME (1996) specification for a drawing to level III requires a higher than normal level of detail, such as showing where the correct door swings are along with associated door cases as well as window sash boxes and the like, all located accurately and correctly within their openings. Beams and other spanning structures have to be drawn correctly to show the full interrelationship of the skeletal structure of the building as a whole, together with associated joists where these are exposed.

To recover this level of information from what are often difficult survey conditions (nothing is square, level or plumb, walls are never a consistent width, there are numerous 'lost' spaces etc) needs a mixture of techniques to achieve a satisfactory result. Hand measuring still remains a costeffective option in small, multi-cell/room situations where it would be costly to keep setting up and re-siting a total station or similar equipment. Advances in software are eroding this problem, however, with the use of hand-held measuring devices which can log general cell dimensions and then be downloaded to a computer, but these still cannot be used readily for recording small or fine details such as door cases, beam splay dimensions and similar architectural features. In larger spaces, plotting with a total station in real time to a laptop can be very cost-effective and 


\section{Modern survey techniques applied to historic sites}

also extremely beneficial for tying in elements such as floor levels through stairwells and rooms off corridors and landings. In very large internal areas laser scanning or photogrammetry can show cost advantages, but these need to be carefully considered and used selectively to be most beneficial in terms of product delivery, time and other cost considerations. In some situations it may be advantageous to combine all these methods to achieve the most satisfactory results.

Externally there is a similar wide choice of survey and data recovery methods available and comparative principles apply with the size/scale of the survey/building being the deciding factor. Hand measuring can be viable in some situations for general working and still will be an indispensable part of the survey for getting into small or otherwise inaccessible areas and for recording details even when more technical methods are employed. Similarly, as for internal working, total station plotting in real time is a very useful tool for the historic building surveyor. It can be used where the levels of the façade and other elements are so irregular that a constant review of survey results is necessary to ensure the correct capture of data. In a large number of situations, laser scanning is becoming a favoured tool as this can result in a tremendous amount of very accurately captured measurement data from which it is possible to produce a set of elevations of a quality to match the plans. Even that is not the complete answer, however, as both of the techniques discussed previously are needed to survey in 'shadow' areas where the scanning beam cannot reach due to it requiring a direct line of sight from the machine.

When using a laser scanner, a tremendous quality of raw survey data can be captured, as mentioned above, which is often more than is initially required. The bulk of the scanned information is left as raw data (see Figure 3) that can be subsequently 'mined' for relevant high-quality results as and when needed and can be used for many purposes involved with the restoration or alteration of the building. The advantage of

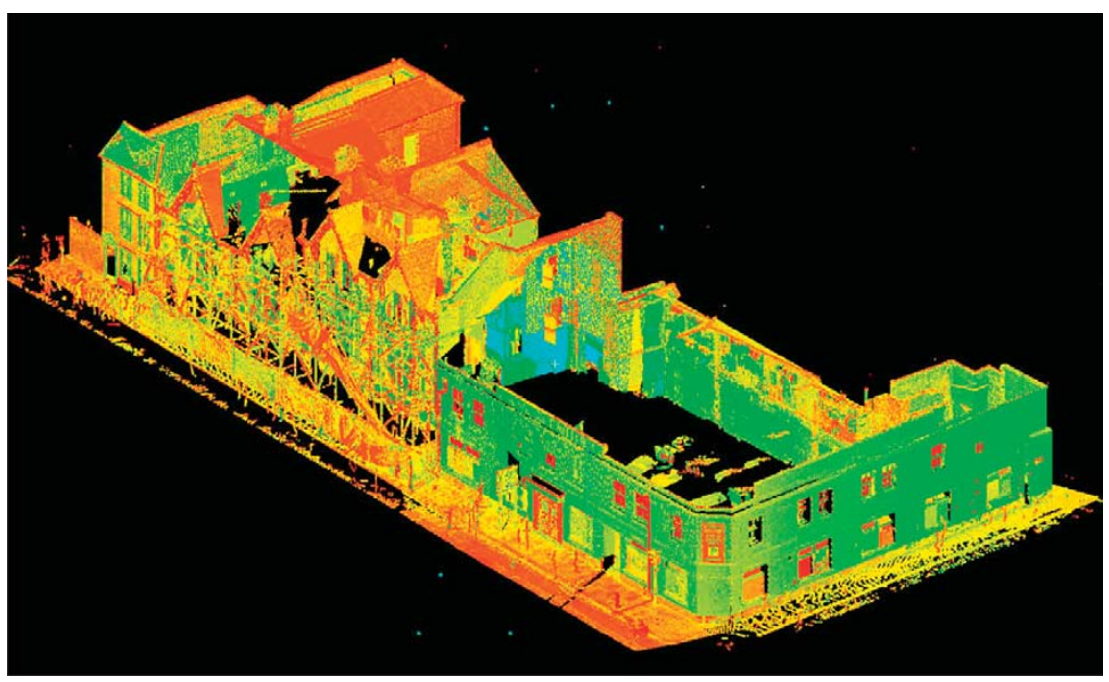

Figure 3: Laser scan 'point cloud' of the elevations of the group of buildings shown in Figure I 


\section{High quality survey results}

working in this manner is that the costs of the external survey and drawing production are kept down in the early stages of the job because all the information is 'safe' and only needs to be processed as it is needed to provide an increasing level of intricacy as the design work proceeds. Outputs can range from simple block plans and elevations to full threedimensional models for walk or fly-arounds, all of which are to very high levels of metric accuracy. As a result, the initial survey costs can be kept down as they do not need to cover the full range of post-production fees which can then be spread over the job, only being encountered as a particular level of information or set of drawings is required and processed.

\section{DRAWING PRODUCTION}

The production of plan drawings has, to a large extent, been discussed above in the context of the level of survey information that is included within them. In simple production terms there is little to mark them out from standard survey drawings as they are produced in exactly the same way using either pen and ink on a drawing board or CAD in an electronic environment. What does mark them out is the level of survey information they contain (see Figure 4). Not just the obvious features of a room are included (accurate door cases and joinery details, overhead beams, floor joist spanning etc) but also interpretative and often hidden information such as door and window blockings and phasing, construction joints and other similar features.

A set of typical or even special sections of the building can be produced from a combination of the results of the internal measured survey and the

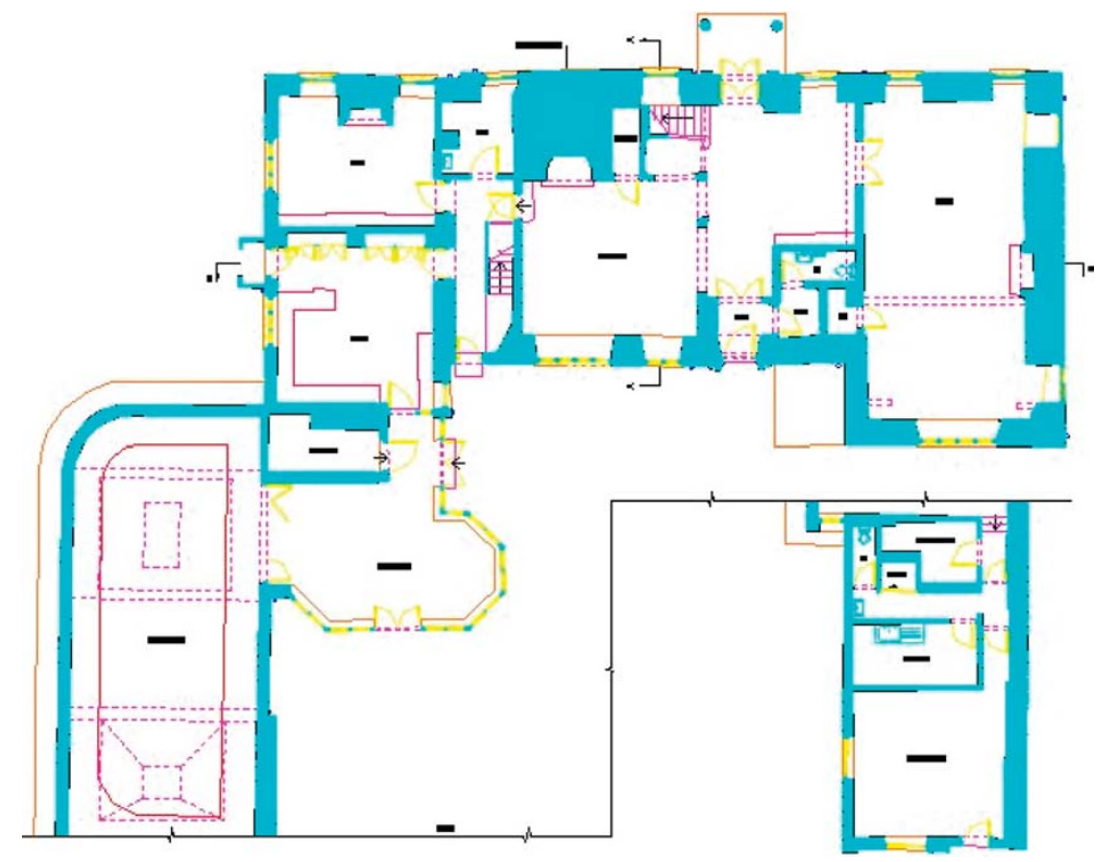

Figure 4: A typical floor plan of a house developed between the 12th and 20th centuries drawn to a combination of BSI I 92 (BSI, 1998), RCHME (1996) specification level III and English Heritage (2003) guidance 
Industry quality drawing output

\section{Cost effective drawing production}

external scanned elevations. Relative heights of ceilings and levels of floors, ceilings, window sills and the underside of beams are all shown where applicable on the sections. Internal finishes will be related to the section drawings and externally all finishes will be noted on the elevations.

Because of the accuracy of the scanning equipment, the density of the cloud of scanned points (the places where the laser beam is reflected back from the building) is variable to an almost infinite degree, which means that incredible levels of detail can be achieved. For most commercial purposes a point cloud (the direct result of the laser scan survey processed into graphic terms) with an effective accuracy of $\pm 10 \mathrm{~mm}$ is normally considered acceptable, although if time (and with it cost) is not a problem then even micron levels can be achieved.

In many respects the information recovery method from a laser scan is similar to that from a traditional hand measure in as much as it needs to be processed post-survey. The only difference is that the basic point cloud, after simple processing, can resemble a somewhat ghostly threedimensional image of the building (see Figure 5), while a set of hand notes comprises just flat pieces of paper. In processing the hand-written notes, data are transferred to paper by the standard method of building up a drawing line by line, a process which has not changed greatly between a drawing board and a CAD screen. To extract elevations from a laser scan it is only necessary to orientate the relevant elevation to a suitable viewing plane and then just trace off the lines of points/dots from the point cloud. With suitable manipulation obscuring features such as scaffolding in front of a façade can be electronically removed to reveal a plane elevation before copying/tracing commences (see Figure 6). In comparison, the use of real-time plotting from a total station enables the basic drawing to be developed as the work proceeds and then only finishing is required upon returning to the office.

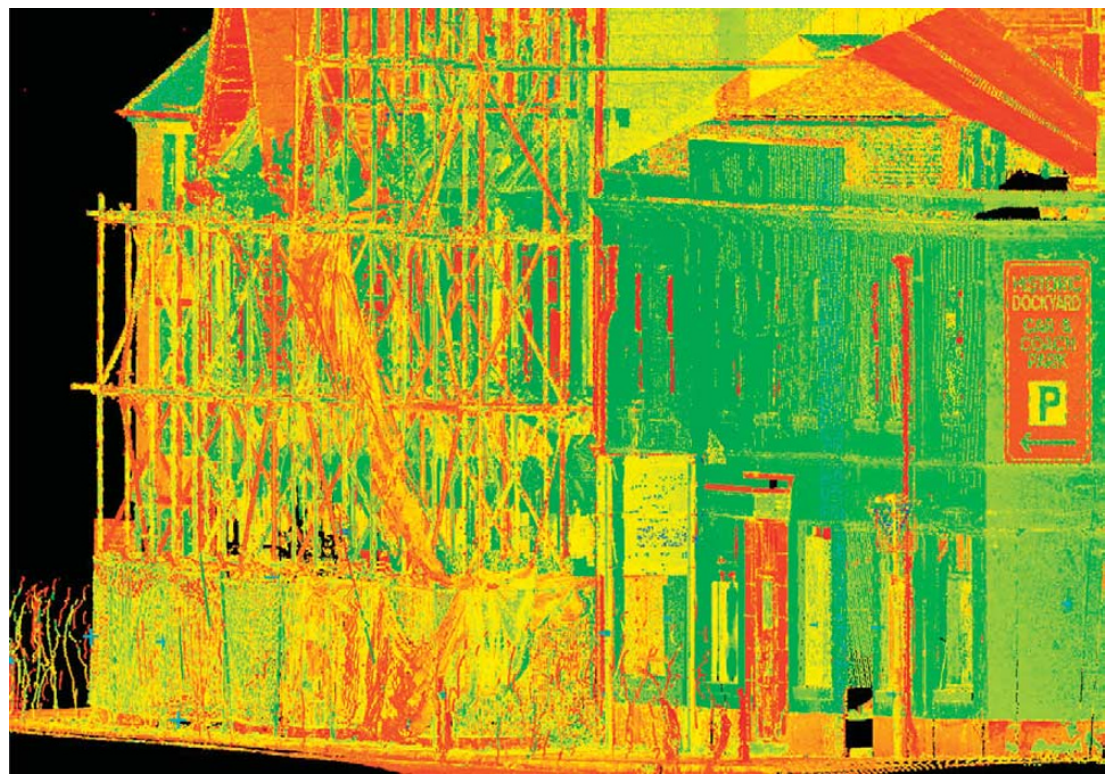

Figure 5: Detail of building elevation laser scan showing scaffolding and screen sheeting 


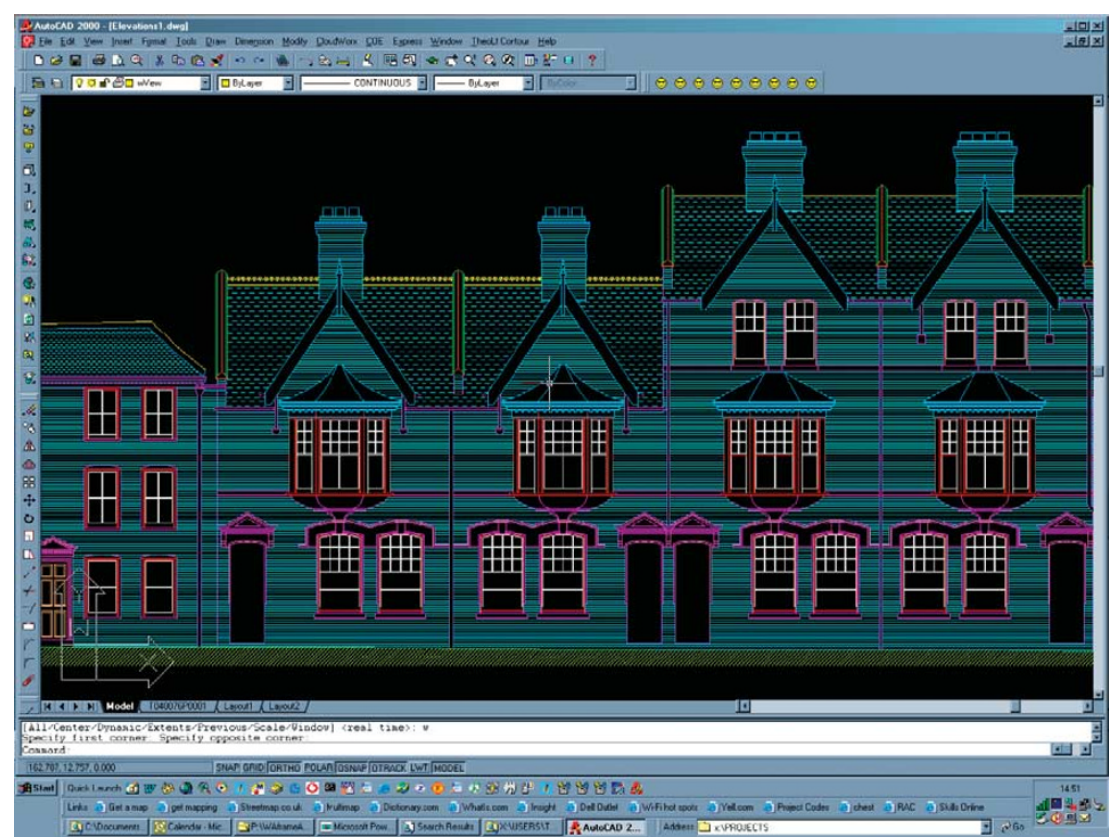

Figure 6: Elevation of buildings in CAD format after electronic removal of scaffolding and screening

Overall, the drawings produced from this level of historic building survey are closer to art than they are to an engineer's plans as the extent of the information contained in them is far greater than commonly produced. Guidance for drawing presentation for historic building surveys is still in its infancy, but some is available from English Heritage (2003). It is this level of detail that is necessary to give designers the fullest information needed if they are to respect the heritage fabric. Similarly, it is the detail that can come out of the survey, combined with the results of the DBA, that form the basis of the historical evaluation phase of the historic building survey.

All drawings should be produced to an architectural/property industry standard and usually be delivered in electronic format. As a minimum level this should comply with BS1192 (BSI, 1998). Delivery is usually in AutoCAD, DXF or similar format as set out in the project brief or as agreed with the client or design team at the outset of the survey. This allows all delivered information to be fully integrated with that of the designer from the very outset of the project. Hard copy delivery of all information can be made also, if required.

\section{REPORT AND ARCHIVE}

On completion of the historic building investigation, a report will be prepared which will collate all the information from the survey. It will address the aims of the building recording programme and will include photographs from the archive as appropriate. It is this report that forms the core of the delivered product and is more than just a set of floor plans and elevations. 


\section{Use the recovered information again and again}

\section{Insurance-backed standards}

Drawings will be produced to an industry standard for architectural work, within a CAD environment. This process will take account of the standards and specification contained in the brief or agreement with the designer/client at the outset of the project. Subsequently, drawings can be delivered in an electronic format (AutoCAD, DXF etc) as agreed, in addition to those included as hard copy within the final report.

The point in the development process at which the work has been commissioned will determine what further use will be made of the report from this point on. If it is the result of a planning consent condition then, generally, it will be consigned to the archives and just filed away, with the client muttering into their tea that this is another waste of time and money brought about by political correctness and the heritage lobby. If, as is becoming more frequent, the report is commissioned at an early stage in the design process then it will be possible to use it quite extensively throughout the design, planning/regulation stage and construction process. This situation can result in the information being used repeatedly and beneficially in various ways by the design, construction and marketing professionals right up to the completion of the capital project. A good report even can have an impact well after the completion of the site in terms of a lasting legacy of information about the heritage of the site and contribute to its sense of place.

At some point following the production of the historic building survey, a copy of the report probably will be deposited within the appropriate county or city Sites and Monuments Records (SMR), particularly if the survey firm is a member of the IFA's registered contractor scheme, where deposition is required by the Institute's bylaws. The SMRs form a national repository system for information coming from investigations into historic sites and may include anything from a 'find' of a Roman coin or prehistoric flint arrowhead to the results of highly organised academic archaeological excavations. At present there is a general re-organisation of these offices taking place. They are going online and are becoming known as Heritage Environment Records to reflect their widening role as a heritage collation source.

Where historic building surveys are instigated by a planning condition, it is normal for there to be a requirement to deposit at least one copy of the resultant report with the local SMR on completion as well as one being forwarded to the LPA for approval and use as a means of discharging the condition. Once lodged with either body that report is in the public domain and, particularly when in the SMR, it can be freely copied without reference to the originator for the purposes of archaeological research or for Development Control. When a report has been produced from a direct commission from a client, however, the delivered product remains within the normal commercial confidence regime and will be revealed to others only with the appropriate consents having been sought and given.

On completion of the report, a cross-referenced and internally consistent archive should be produced to keep the entire survey resource safe and in one place. While this may seem an obvious statement it is one that is frequently overlooked or even ignored and can lead to problems 
later with clients who wish to revisit projects or if public deposition of a report is subsequently required as part of an applied planning condition. It is also something that is a general requirement of all professional indemnity insurance (PII) policies.

The archive should be stored appropriately, for example, slides should be stored in archival quality plastic wallets for suspension in filing cabinets. The primary archive, including copies of all photographs and a set of colour slides, also should be retained, but may be deposited elsewhere with a suitable holder in agreement with the client and also the PII providers.

\section{CONCLUSION}

This paper has tried to show the difference between measured surveys undertaken on an historic building in a traditional manner and those that are specifically considered to be historic building surveys. This is not just a name that has been derived to signify what is being surveyed, but illustrates the specialisation and knowledge recovery that is now expected from a survey of an historic building. From this form of survey, when carried out correctly, a very wide range of information can be recovered for the equally extensive benefit of the construction team.

To be fully effective an historic building survey needs to be produced as early in the design stage of a project as possible. The later the information is recovered the less use can be made of it and so it becomes of reduced cost-effectiveness. In extreme cases, when the survey has to be done after

Time and money saving the design is complete and as physical work is about to start, it often duplicates what has been done previously with a similar replication of fees. Then the most galling aspect for some clients is when new information is recovered, too late, that could have made a significant difference to the project in timing or financial terms (or both) had it been known earlier.

It is also important to consider the abilities of the surveyors who are commissioned to carry out the work, in terms of their full abilities not just a simple fee quotation. As with any consultant there is a need to be able to explain clearly what the results of the survey are, interpret them in language understandable to the design team and, most importantly, be able to provide thoroughly reasoned and commercially sound conservation advice. At the completion of a project a level of service should have been delivered that provides many beneficial financial gains including reduced development time, interest-charge savings and early sales/rental returns. These savings often can be equivalent to the historic building surveyor's fees, making it effectively a free service.

\section{Acknowledgments}

The author would like to thank Chris Brayne (head of IT and surveying, Wessex Archaeology) for his comments on this paper's content and also all those at Warner Land Survey Limited for their contribution to its writing. 


\section{References}

British Standards Institute (BSI) (1998) BS1192, Construction Drawing Practice, BSI, London, UK English Heritage (1993) The Presentation of Historic Building Surveys in CAD. XH20129, English Heritage, Swindon, UK.

English Heritage (2003) Measured and Drawn - Techniques and Practice for the Metric Survey of Historic Buildings, English Heritage, Swindon, UK.

Office of the Deputy Prime Minister (ODPM) (undated) Planning Permission Guidance Note 15. Planning and the Historic Environment, ODPM, London, UK.

Office of the Deputy Prime Minister (ODPM) (undated) Planning Permission Guidance Note 16. Archaeology and Planning, ODPM, London, UK.

Royal Commission for the Historic Monuments of England (RCHME) (1996) Recording Historic Buildings - A Descriptive Specification, RCHME, Swindon, UK.

\section{Further reading}

Historic Environment Local Management (HELM), available from www.helm.org.uk.

Institute of Field Archaeologists (IFA) (current) Standards and Guidelines for the Archaeological Investigation and Recording of Standing Buildings or Structures, IFA, Reading, UK.

Institute of Field Archaeologists (IFA) (current) Regulation of Archaeological Organisations, IFA, Reading, UK.

Institute of Field Archaeologists (IFA) (current) Standards and Guidance for Desk-based Assessments, IFA, Reading, UK.

Office of the Deputy Prime Minister (ODPM) (1990) The Planning (Listed Building and Conservation) Act, ODPM, London, UK.

Swallow, P., Watt, D. and Ashton, R. (1993) Measurement and Recording of Historic Buildings, Donhead, Wimbledon, UK. 